\title{
Test study on thickness of soil layer at top of plate affecting uplift failure of the NT-CEPP
}

\author{
Yongmei Qian, Jiyuan Zhang, Ruozhu Wang*, Yujie Jin \\ Jilin Jianzhu University, Changchun, Chinese \\ * Corresponding author.
}

\begin{abstract}
This paper studies the influence of the thickness of the soil layer on the head of the plate on the carrying capacity of the new type concrete plates-expanded pile (NT-CEPP) under vertical tension, and innovatively uses the half-section pile test method to measure undisturbed soil and ANSYS is used for comparative analysis. Due to the small-scale test based on the half-section pile and disturbed soil, not only can the overall invalidation mechanism of the soil around the pile be seen more clearly, but the undisturbed soil can also be used to better ensure the stability of the soil. At the same time, in the test, depending on the real station under construction, the authenticity and economy of the test should be ensured. The results of test reveal that the invalidation behaviour of the on the top of plate of the NT-CEPP has little effect on the adjacent soil layer when the soil thickness of embedded slab is more than 3 times the length of the cantilever of the slab, and the characteristics of adjacent soil-layer had no influence on the carrying capacity of the plate.
\end{abstract}

Keywords: the new type concrete expanded-plates pile (the NT-CEPP), soil thickness, uplift failure, half-section piles, test of undisturbed soil.

\section{Introduction}

In recent years, the NT-CEPP has been more broadly apply to practical engineering because of their higher economic, environmental and social benefits ${ }^{[1-3]}$. The digging and squeezing equipment indicate that the forming equipment of NT-CEPPs has developed to a relatively mature stage, which has promoted the research and development of pile foundations ${ }^{[4]}$.Compared with the development of equipment to form the NT-CEPP, the theoretical research is still in a relatively preliminary stage. After a further deep research, it has been put forward that the bearing capacity of NT-CEPPs consists of pile tip resistance, pile side friction, and plate-end resistance ${ }^{[5]}$. When the axial load on the pile becomes larger, the pile-soil interface will fail ${ }^{[6]}$. As the soil which is compacted under the plate is continuously carried out along the edge of the plate and begins to return after reaching a certain state, the scope of the compacted soil presents generally heart-shape distribution. Therefore, it is more practical to use the plastic potential energy theory, the imaginary number principle and the slip line theory to calculate the end resistance of the plate ${ }^{[7-9]}$. At the same time, the space, number and inclination of the slab are also considered in the calculation formula for the bearing capacity of a single pile, which makes the calculation formula for the bearing capacity of a single pile NT-CEPP more abundant and more mature ${ }^{[10]}$.

However, up to now, only the calculation formula for the compressive or uplift carrying capacity of one NT-CEPP has been given. When NT-CEPP is under horizontal load at home and abroad, the bearing mechanism of NT-CEPP has not been put forward reasonably ${ }^{[11]}$. At the same time, if the group effect of the pile will occur when the space of the NT-CEPP is closer ${ }^{[12]}$. How much the minimum space is in order to avoid the group effect of the pile; when the pile group effect is unavoidable under the external objective conditions, what number of reduction factor should be used for calculating the ultimate bearing capacity of the pile, all of above problems are not fully demonstrated from the current theoretical achievements.

ISSN: 0010-8189

(C) CONVERTER 2020

www.converter-magazine.info 
In the calculation formula of bearing capacity of the single NT-CEPP, features of a pile body, such as the space, the number and the slope angle of plate etc., are taken into consideration, but the soil properties around the pile such as the soil thickness of upper and lower of plate, moisture content, plasticity index, liquid index and temperature, etc. have not been properly considered in the calculation formula of bearing capacity of the NT-CEPP ${ }^{[13-16]}$. At present, the study on the mechanical properties and failure mechanism of the pile is about bearing plate embed in the cohesive soil layer ${ }^{[5]}$. In fact, the different sites have different soil thickness, and it needs to be further studied that the influence factors for the NT-CEPP due to different and adjacent the top of soil thickness layer.

In this paper, pile based model test with a single plate, different test models of the NT-CEPP under the vertical tension will be built ${ }^{[17-18]}$. Through the model test with the undisturbed soil, the effect of the soil thickness layer at the top of the plate is studied. During the test, through recording the displacement, loading data, taking photos and observation of the destructive behavior of the pile and soil, the obtained data and images will be sorted and analyzed.

\section{The Preparation and Process of Test}

\subsection{Design and manufacture of test device}

\subsubsection{Design of loading test device}

The study will conduct small model tests on the uplift of NT-CEPPs of half-section piles. Since the traditional test equipment cannot meet the test demand, a multifunctional test equipment is designed, which is shown in Fig. 1.

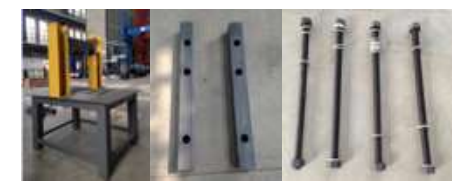

Fig 1: Multi-function test device and accessories

\subsubsection{Design of device for getting soil sample}

As the test is conducted on undisturbed soil, so a device for obtaining soil samples is specially designed to obtain undisturbed soil. In order to ensure that the equipment will not be deformed, 3-mm-thick Q235 steel has been chosen as the material of the device for getting soil samples ${ }^{[19]}$. Fig. 2. shows the design model diagram of the equipment and clamp (used to fix the glass and steel plate when installing the glass) to obtain the soil sample. Table 1 lists the dimensions of the different equipment used to obtain soil samples.

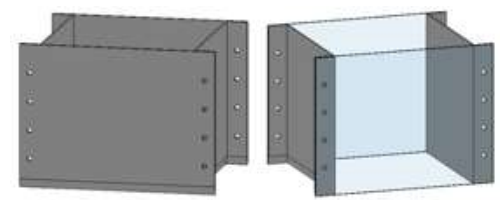

Fig 2: Model diagram of the device for getting soil sample

Table 1 The size of the device for getting soil sample

\begin{tabular}{|l|l|l|l|l|}
\hline & Length, $\mathrm{mm}$ & Width, $\mathrm{mm}$ & Height, $\mathrm{mm}$ & Thickness, $\mathrm{mm}$ \\
\hline
\end{tabular}

ISSN: 0010-8189

(c) CONVERTER 2020 
Volume 2021, No. 2

\begin{tabular}{|c|c|c|c|c|}
\hline Uplift(Silty clay) & 300 & 200 & 120 & 3 \\
\hline Uplift(Hard clay) & 300 & 200 & 200 & 3 \\
\hline
\end{tabular}

Note: The edge of the flat steel plate is the length, and the I-steel side is the width.

\subsubsection{Design of the pile}

Since this is a small-scale model test and it is assumed that the soil has been destroyed before the pile, the material of the test pile has little influence on the test results. Therefore, Q235 steel is used for the test pile model, and its size is shown in Table 2.

Table 2 The size of the test model pile

\begin{tabular}{|c|c|c|c|c|c|c|}
\hline & WAPP & PID, $\mathrm{mm}$ & PLD, $\mathrm{mm}$ & PH, $\mathrm{mm}$ & CL, $\mathrm{mm}$ & PL, $\mathrm{mm}$ \\
\hline APS & - & 500 & 1500 & 750 & 500 & --- \\
\hline UPS & $1: 50$ & 10 & 30 & 15 & 10 & 360 \\
\hline
\end{tabular}

Note: APS: actual pile size, UPS: uplift pile model size, WAPP: the proportion of the model with actual pile, PID: pile diameter; PLD: plate diameter, PH: plate height, CL: cantilever length of the plate, PL: pile length.

\subsection{The process of model test of undisturbed soil}

The uplift test of NT-CEPP is more complex than that of compression, and a large number of auxiliary components are needed to achieve. First of all, the soil sample collection device is fixed on the loading platform through the buffer beam and the connecting rod, so that the device will not move with the multifunctional loading platform. Secondly, the key step is to need a tie rod with one end connected to the deck end of the pile, and the other end passes through the beam and the jack, as well as the body of the tie rod has some equal small round holes that can be inserted by stud bolts. Finally, the jack is placed on the beam and the stud is inserted into the hole of the pull rod to fix the location of it, thereby forming a pulling device, and then the NT-CEPP as shown in Fig. 3 can then be carried out ${ }^{[20]}$. Since the small holes of the pull rod are distributed at equal distances, multiple hollow spacers can be used to adjust the height of the hollow jack.
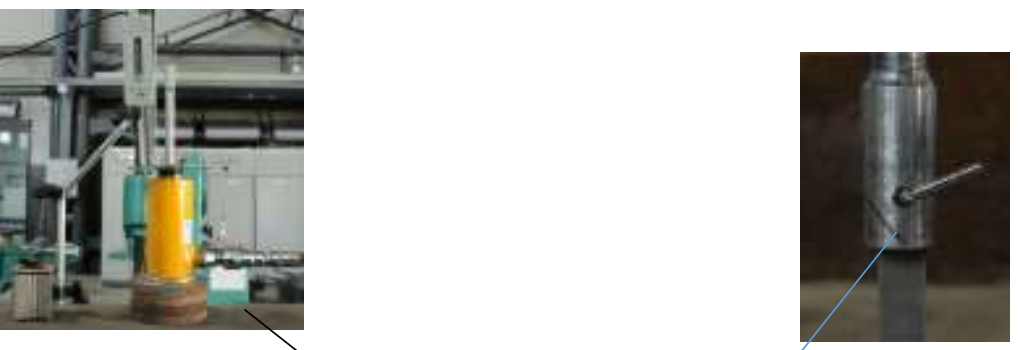
Fig 3: The loading device of pulling test

The hollow gasket is shown in the upper left of Fig. 3. In the top right corner of Fig. 3, one end of the pull rod is connected to the half-section pile, in which small holes is corresponding to symmetrical small holes on both sides of the pull rod, with a thin stud passing through the holes. The other end of the pull rod passes through the jack, and the upper end of the jack can be restrained by using a thin bolt through the hole in the pull rod. It can be ensured that the half-section pile can guarantee the vertical upward force through the pull rod.

\section{Analysis of Test Results}

Under the action of vertical tension, the thickness of the embedded slab soil layer plays a significant role in the bearing capacity of NT-CEPP ${ }^{[21]}$. Therefore, the test focuses on the influence of the soil thickness on the upper part of the slab on the bearing capacity of the NT-CEPP by changing the thickness of the upper soil in the soil layer of the embedded slab. The soil thickness layer above the board is divided into four cases: 2 times the length of the cantilever of the plate (the length of the cantilever is the linear distance of the protruding part of the plate), 3 times the length of the cantilever of the plate, 5 times of it, and 6 times of it, and so on. The test results will be studied and analysed.

\subsection{Failure behaviour of soil around pile}

First, by observing the failure behaviour of soil around the pile through the whole process from the beginning of loading to failure of the No.7 pile, the pile-soil destruction process shown in Fig. 4 can be clearly seen.
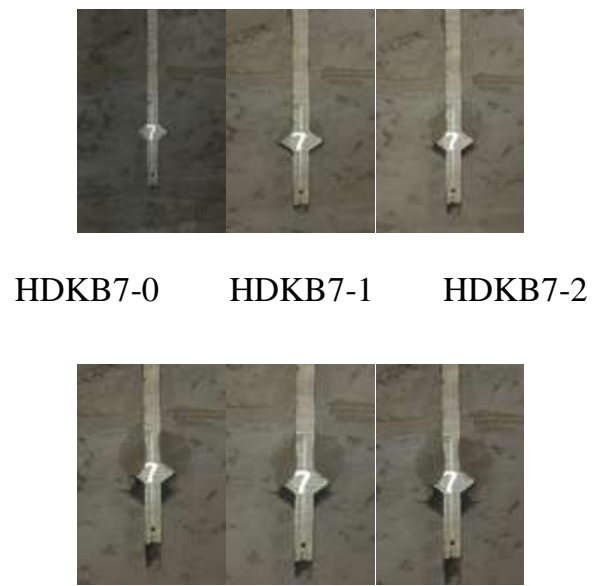

\section{HDKB7-3 HDKB7-4 HDKB7-5}

Fig 4: The picture of the failure behavior of model pile in pulling test (taking an example of No.7 pile)

It can be clearly seen from Fig. 4 that the destruction behavior and destruction process of the soil around the pile and the destruction process of NT-CEPP under tension can be divided into three stages.

The first stage is the elastic compaction stage. At this stage, in the early stage when the model pile is loaded, the load is small, and the soil above the plate is compacted in the triangular area (as shown in HDKB7-1 of Fig. 4).

The second stage is the plastic deformation stage. In this stage, the model pile test enters an intermediate stage. At this time, the load on the top of the pile gradually increased, and microcracks occurred at the end of the plate. A "heart-shaped" compressed area appears on the top of the plate, which gradually increases to form an obvious ISSN: 0010-8189

(C) CONVERTER 2020

www.converter-magazine.info 
sliding line region (as shown in HDKB7-2 HDKB7-4 in Fig. 4). Compared with ordinary pile, NT-CEPP increases the bearing plate, which increases the interaction between the pile and the soil, reduces the vertical displacement of the pile. With the increase of load, the shear failure of the pile end gradually increased, the slipping of the soil occurs on the top of the plate, and the upward displacement of the pile gradually increases.

The third stage is the failure stage. The static load test has entered the later stage, and the displacement of the pile has changed greatly under a small incremental load (see HDKB7-5 in Fig. 4). The model pile can no longer bears the load, and the soil around the pile is seriously damaged at this time, so the load has reached the limit. The test is over.

In summary, it can be seen from the pulling test of the whole process that with the increase of the vertical load on the NT-CEPP, the watermark on the top of the plate can clearly see the failure behavior of the soil on the top of the plate. Obvious slid lines appear on the top of the plate and the soil around the piles, indicating that with the increase of vertical tension, the soil on the top of the slab gradually reaches failure behaviour along the slip line.

3.2 To compare the failure behavior of soil around different model piles

The results reveal that the undisturbed soil test with the soil thickness layer of embedded slab will affect the failure behavior of NT-CEPP, and the destruction situation of soil around different piles is shown in Fig. 5 and Fig. 6.

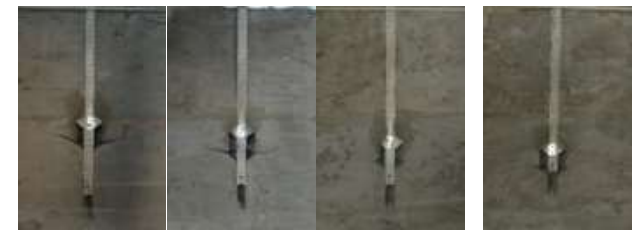

Fig 5: The picture of failure of the different model pile
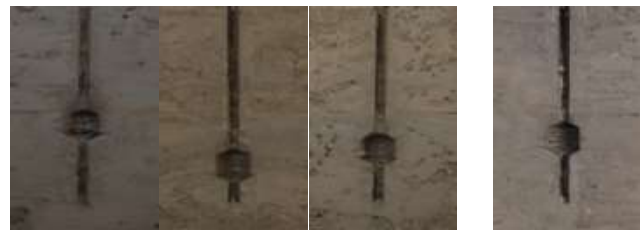

Fig 6: The soil conditions when destructed

It can be seen from the figure that the similarities of failure of the soil around different pile are as follows:

(1) Since the soil itself has a certain degree of plasticity, in the initial stage of loading the vertical tension, the soil on the top of the model pile in the HDKB1-HDKB4 picture on the plate is compressed under the vertical tension ${ }^{[22]}$. Within the elastoplastic limit deformation range of the undisturbed soil, as the pile displacement increases, the soil on the top surface of the plate gradually becomes dense. In the process of compressing the soil, shear failure occurs in the soil at the edge of the support plate, the soil on the top of the plate is compacted, and as the load increases, the compacted soil appears a "heart-shaped" area, in which slip lines develop.

(2)For the soil under the slab, the bottom surface of the load-bearing plate is immediately separated from the soil for the model piles tested in the early stage of vertical stress, but it will not cause damage to the soil under the plate. This conclusion is consistent with the previous results of the NT-CEPP uplift test.

ISSN: 0010-8189

(C) CONVERTER 2020

www.converter-magazine.info 
(3)For the soil on the top of the plate, when the compression reaches the elastic-plastic deformation limit of the soil, the soil on the top of the plate will lead to sliding failure, which shows as the sliding line $\theta$ (the acute angle between the tangent direction and the horizontal line) is symmetrically unfolded relative to the outside of the pile at the edge of the slab and along a certain angle.

(4)When the model pile in picture HDKB1- HDKB4 is loaded into the soil damage (the sliding failure), the soil failure behavior at the top of the model pile plate is similar. The measured horizontal distance between the outermost edges, the sliding crack and the axis of symmetry of NT-CEPP are the influence range of the bearing plate on the soil at the top of the plate, which is about 4 to 5 times of the cantilever length of the plate. This conclusion is consistent with the results of previous Uplift Tests of NT-CEPPs.

It can be seen from the figure that the different points of failure of soil around different piles are as follows:

In the pile-soil interaction, soil layers of different thickness have different effects on the bearing capacity of NT-CEPPs. By observing the boundary between the two soil layers in the picture, under vertical tension, the boundary of the picture HDKB1 is obviously protruding. However, the boundary between HDKB2 and HDKB3 is not significantly convex, and the boundary of HDKY4 remains unchanged. Therefore, from HDKB1 to HDKB4, the impact of NT-CEPPs on the upper soil is getting smaller and smaller. When the thickness of the soil layer on the top of the plate is three times the cantilever length of the plate, the effect of the NT-CEPP on the upper soil is almost non-existent.

When the soil on the top of the plate is damaged due to sliding failure, the soil around the edge of the plate will produce a sliding line, and the angle (acute angle) $\theta$ between the tangent line and the horizontal line along the sliding line is known as the sliding angle. It can be seen from the figure that the slide angle of HDKY1 is small, and the sliding curve has the development trend of horizontal direction.

\subsection{Analysis of data of displacement- load curve}

From the test data, the load and displacement curves of NT-CEPP are obtained by uplift test, as shown in Fig. 7 and Table 3. It can be seen from the curve in Fig. 7 that in terms of uplift resistance, the displacement of different NT-CEPPs increases with the increase of load. Under the same load, with the increase of soil layer thickness at the top of plate, the pile from HDKB1 to HDKB4 gradually increases.

In the early stage of uplift test of NT-CEPP (the displacement of pile top is between $0 \sim 1 \mathrm{~mm}$ ), the load changes suddenly. The load of HDKB1 HDKB4 varies greatly, but the gradient change is small. Under the action of vertical tension, the soil is compacted by squeezing to increase the initial bearing capacity of the soil and increase the unit displacement under the action of vertical tension. This is consistent with the result that the gradient of the load-displacement curve is the maximum gradient in the entire curve.

In the middle of the test (the displacement of the pile top is between 1 and $10 \mathrm{~mm}$ ), the increase in the vertical tension of the pile top gradually tends to be gentle. As the vertical tension increases, the soil at the end of the slab begins to crack slightly, destroying the integrity of the soil. The bearing capacity drops to a certain extent, and the slope of the final load-displacement curve becomes slower.

In the final stage of the test (the displacement of the pile top is between 10-24 mm), the soil cracks further expand with the increase of the vertical tension of the pile top. Next, the soil at the top of the plate is separated from the soil around the plate along the sliding line. The soil at the top of the plate slides relatively and the vertical tension reaches the limit of soil bearing capacity. In comparison, the load can increase slowly, but the displacement of the

ISSN: 0010-8189

(C) CONVERTER 2020

www.converter-magazine.info 
Volume 2021, No. 2

pile will increase rapidly, and the load and displacement will increase linearly in the final stage. In addition, because the vertical load may not reach the ultimate bearing capacity of the soil, the shear failure between the plate and the soil occurs, and the displacement caused by the load increases linearly, and the excessive displacement of the pile body is also a kind of damage.

Table 3 Displacement load data of tensile pile test

\begin{tabular}{c|c|c|c|c|c|c|c|c|c}
\hline & HDKB1 & HDKB2 & HDKB3 & HDKB4 & & HDKB1 & HDKB2 & HDKB3 & HDKB4 \\
\hline 0 & 0 & 0 & 0 & 0 & 0 & 0 & 0 & 0 & 0 \\
\hline 1 & 0.225 & 0.288 & 0.276 & 0.263 & 14 & 0.485 & 0.515 & 0.559 & 0.610 \\
\hline 2 & 0.258 & 0.298 & 0.311 & 0.272 & 15 & 0.506 & 0.522 & 0.58 & 0.642 \\
\hline 3 & 0.310 & 0.332 & 0.355 & 0.324 & 16 & 0.506 & 0.543 & 0.582 & 0.654 \\
\hline 4 & 0.328 & 0.350 & 0.387 & 0.380 & 17 & 0.527 & 0.555 & 0.596 & 0.667 \\
\hline 5 & 0.354 & 0.382 & 0.412 & 0.420 & 18 & 0.534 & 0.567 & 0.616 & 0.676 \\
\hline 6 & 0.359 & 0.396 & 0.442 & 0.457 & 19 & 0.553 & 0.577 & 0.626 & 0.712 \\
\hline 7 & 0.393 & 0.415 & 0.455 & 0.474 & 20 & 0.558 & 0.588 & 0.652 & 0.717 \\
\hline 8 & 0.400 & 0.434 & 0.475 & 0.494 & 21 & 0.558 & 0.605 & 0.660 & 0.732 \\
\hline 9 & 0.424 & 0.453 & 0.488 & 0.523 & 22 & 0.592 & 0.615 & 0.678 & 0.763 \\
\hline 10 & 0.431 & 0.463 & 0.507 & 0.533 & 23 & -- & 0.667 & 0.706 & 0.782 \\
\hline 11 & 0.452 & 0.481 & 0.513 & 0.568 & 24 & -- & 0.667 & 0.718 & 0.795 \\
\hline 12 & 0.470 & 0.490 & 0.535 & 0.576 & 25 & -- & -- & 0.743 & 0.808 \\
\hline 13 & 0.479 & 0.513 & 0.542 & 0.593 & 26 & -- & -- & 0.759 & -- \\
\hline
\end{tabular}

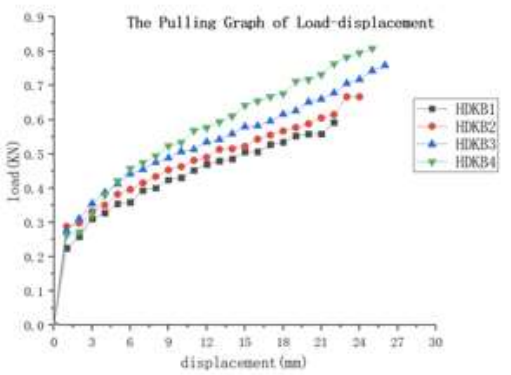

Fig 7: The load - displacement curve of different model pile

\section{The Comparing Analysis by Finite Element}

4.1 Analysis results of finite element

In order to compare the experimental results, the finite element simulation analysis is carried out by using ANSYS software. When the thickness of the upper and lower soil layers is determined according to the model shown in Table 4 and Fig. 8, the influence of uplift bearing capacity and the role of pile-soil are analysed by changing the distance between the plate and the critical interface of two layers of soil, and the failure mechanism of NT-CEPP

ISSN: 0010-8189

(c) CONVERTER 2020

www.converter-magazine.info 
Volume 2021, No. 2

under four different soil thickness is analysed. The six model piles are named HDKB1(two times cantilever length of the plate), HDKB2(three times cantilever length of plate), HDKB3(five times cantilever length of plate), HDKB4(six times cantilever length of the plate), and the corresponding test pile types are No.5 to No.8.

Table 4 Model specifications for different types of piles

\begin{tabular}{|c|c|c|c|c|c|c|}
\hline \multicolumn{2}{|c|}{ Category of model } & \multicolumn{5}{|c|}{ Specifications of Different Types Model } \\
\hline \multirow{2}{*}{ Hard clay } & \multirow{2}{*}{ Uplift } & Name & HDKB1 & HDKB2 & HDKB3 & HDKB4 \\
\cline { 3 - 7 } & & L & 1000 & 1500 & 2500 & 3000 \\
\hline
\end{tabular}

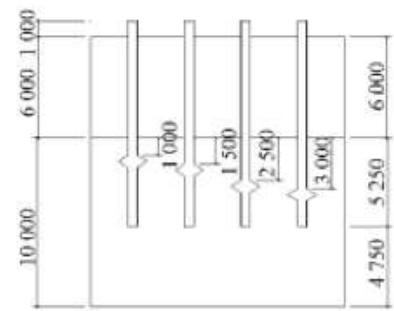

Fig 8: Dimension diagram of model with different soil-layer thickness under vertical tension

With the increase of load, the vertical displacement of pile under different loads is analysed. Through the simulation, it is easy to get the displacement curve with the load through the vertical displacement data of the pile under different loads, as shown in Fig. 9.

It can be seen from the curve in Fig. 9 that the displacement has little change at the beginning of loading. The displacement of the pile increases with the increase of load, and sometimes a linear relationship can be formed in a certain range. Then, with the increase of load, the change rate of displacement increases gradually. Under the same load, as the soil thickness layer on the top of the slab increases, the displacement of the pile gradually decreases. The displacement of HDKB1 is the largest, and that of HDKB4 is the smallest. Comparatively, the load-displacement curves of HDKB2 to HDKB4 are basically the same with little change, and the pile displacement is similar under the same load. Therefore, it can be concluded that when the soil layer thickness is greater than a certain thickness, the soil layer of the plate is embedded, and the change of the soil layer thickness at the top of the plate has little influence on the NT-CEPP. According to previous theoretical studies, the effect of soil layer on NT-CEPP is almost the same when the thickness of soil layer is greater than 3 times of cantilever length of plate $^{[15]}$.

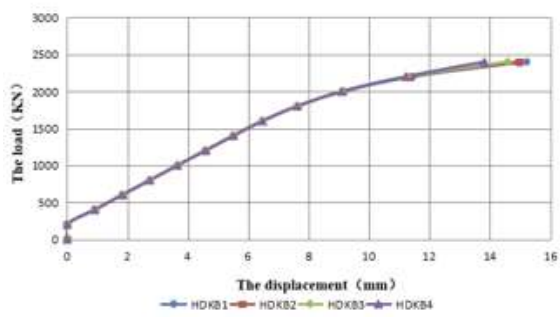

Fig. 9 The displacement-load curves in different thickness of soil-layer

\section{Comparative Analysis of Model Test and Simulation Results}

There is a big difference between the results of model test and simulation analysis, as the simulation analysis is

ISSN: 0010-8189

(C) CONVERTER 2020

www.converter-magazine.info 
completed by ideal computer simulation, and the model test is affected by objective conditions, such as the friction resistance of the lateral limit glass panel in the model test. In addition, factors such as the inhomogeneity of the soil around the pile and the verticality of the load in the test will also cause the difference in the model test results. But in the process of the test, the development trend of the load displacement curve of the pile is similar to the failure behaviour of the soil around the pile, which has a reference value for the study of the mechanical properties of NT-CEPP. The following is an example of HDKB3, which shows the trend of load-displacement-curve for model testing and simulation analysis, as shown in Fig. 10.
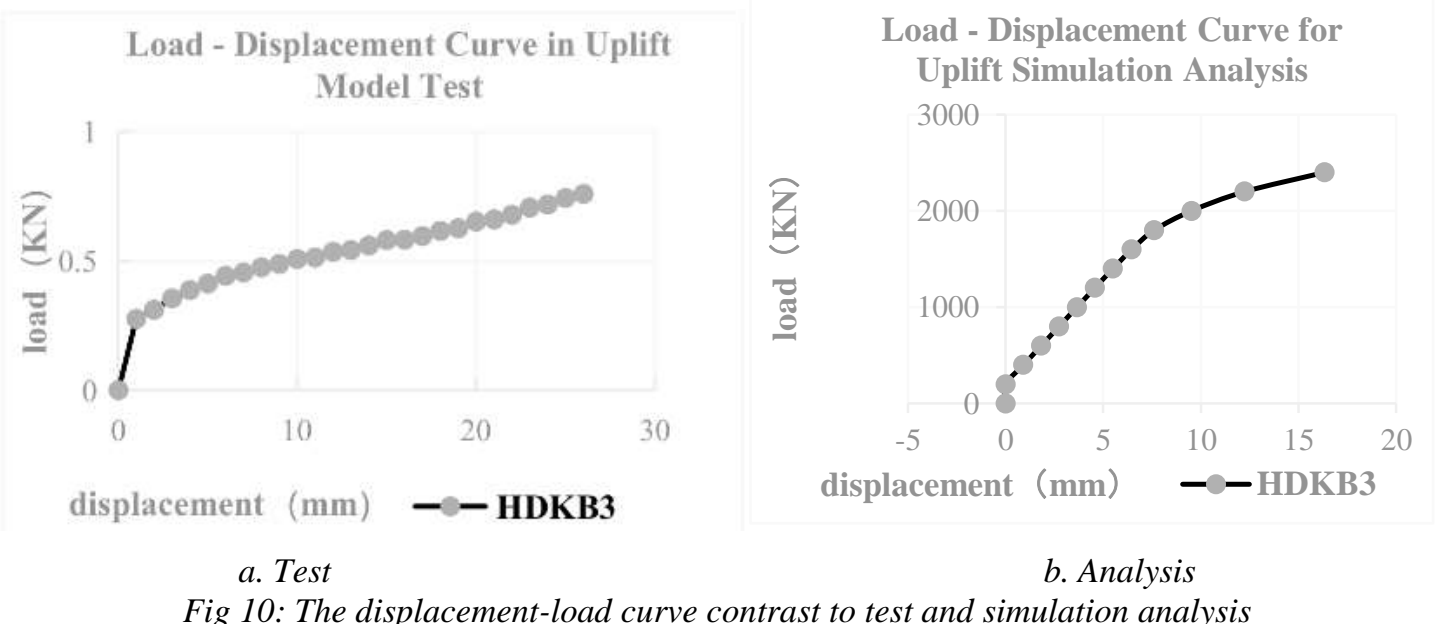

From the comparative analysis of the model test load-displacement curve and the simulation analysis, in the HDKB3 pile uplift test, the load increases with the displacement, and the load shows a convex line change relative to the displacement. Similarly, the simulation analysis of the load of the pile increases with the displacement, and the load also exhibits a convex line change relative to the displacement. The difference is that the model test at the beginning (displacement $0 \sim 1 \mathrm{~mm}$ ) has load mutation, while in the simulation analysis, the load has a mutation but little change in the displacement, this is due to the fact that the displacement increasing is controlled during the test to record the load, and the simulation analysis is by controlling the increase of load to derive the displacement, the difference is better able to verify each other. In summary, the conclusions from the studying of model test and simulation analysis are basically the same.

From the comparative analysis and simulation analysis of load displacement curves of model test, it can be seen that in the uplift test of HDKB3 pile, the load increases with the increase of displacement, and the load changes in a convex line relative to the displacement. Similarly, the simulation analysis of pile load increases with the displacement, and the load also shows a convex line change relative to the displacement. The difference is that the model test has a sudden change at the beginning (displacement $0 \sim 1 \mathrm{~mm}$ ). In the simulation analysis, although there is displacement, the displacement change is very small, which is due to the increase of displacement. During the test process, the millimetre is recorded by control, while the simulation analysis is to convert the displacement by controlling the increase of increment and this difference can be verified better by each other. In summary, the conclusions of model test and simulation analysis are basically the same.

\section{Conclusions}

The main conclusions can be drawn by the research as follows:

(1)When the NT-CEPP is under vertical tension, with the increasing of the vertical tension, the vertical ISSN: 0010-8189 
displacement of the pile is increased, the stress on the top of plate is increased and the position is mainly concentrated on the plate.

(2)For the soil under the plate, the bottom surface of the bearing plate immediately separates from the soil during the initial stage of loading the vertical tension, but does not cause any damage to the soil under the plate.

(3)When the compression account reaches the limit of elastic-plastic deformation of the soil, the soil on top of plate causes sliding failure. Slip lines due to failure were initially observed at the edge of the plate along with a certain angle $\theta$ ( $\theta$ is the acute angle between the tangent line of the sliding line and the horizontal line) develops symmetrically upward.

(4)The failure behavior of the soil on the top of plate of the NT-CEPP has little effect on the adjacent soil layer when the thickness of the soil-layer of the plate embedded is larger than 3 times of the cantilever length of plate, and the characteristics of adjacent soil-layer had no effect on the bearing capacity of the plate. Otherwise, it is necessary to consider the influence of the adjacent soil-layer on the sliding failure of the soil on the top of plate.

(5)In this paper, because of breaking the traditional laboratory embedded soil experiment method, and designed a self-made soil testing equipment, which can be used to remove undisturbed soil from the construction site, as well as a multifunctional loading platform has been designed. All of these can ensure the smooth progress of the test and have important significance for future research.

\section{Acknowledgments}

This research described in this paper was financially supported by National Natural Science Foundation of China (52078239).

This research described in this paper was financially supported by National Natural Science Foundation of China (51678275)

\section{References}

[1] Kumar, Sanjeev, Prakash, Shamsher, "Estimation of fundamental period for structures supported on pile foundations," Geotechnical and geological engineering, vol. 22, no. 3, pp. 375-389, 2004.

[2] Y.M. Qian, J.Y. Sun, Y.J. Jin, R.Z. Wang, "Ecological research on moisture content of clay soil affecting failure behavior of the CEP pile under vertical load," Ekoloji, vol. 27, no. 106, pp. 745-751, 2018.

[3] N.A. Stashevskaya, D.D. Koroteev, M. Kharun, "The technology development of the widened base formation for bored piles," J Fundam Appl Sci., vol. 10, no. 3S, pp. 606-614, 2018.

[4] Global IP News. Tools and Machinery Patent News, "Li Run Applies for Patent on Drilling Bucket Type Pile Digging Device," 2018.

[5] Y. Hong, B. He, L.Z. Wang, Z. Wang, Ng, C.W.W, D. Mašín, "Cyclic lateral response and failure mechanisms of semi-rigid pile in soft clay: centrifuge tests and numerical modeling," Canadian geotechnical journal, vol. 54, no. 6, pp. 806-824, 2017.

[6] G. Russo, "A method to compute the non-linear behaviour of piles under horizontal loading," Soils and foundations, vol. 56, no. 1, pp. 33-43, 2016

[7] F. Khorami, Golnar, Rasoolan, Iraj, "Soil-Pile Interaction Analysis Using Multi-laminate Elasto-Plastic Modelling," Geotechnical and geological engineering, vol. 35, no. 4, pp. 1665-1683, 2017.

[8] J.J. Ma, X.J. Gao, F.J. Liu, "Nonlinear lateral vibrations and two-to-one resonant responses of a single

ISSN: 0010-8189

(C) CONVERTER 2020

www.converter-magazine.info 
pile with soil-structure interaction," Meccanica (Milan), vol. 52, no. 15, pp. 3549-3562, 2017.

[9] X.W. Xie, R.Z. Wang, Y.M. Qian, "Research on the Ultimate Bearing Capacity of Soil about Push-Extend Multi-Under-Reamed Pile at the Compression", Advanced materials research, vol. 718-720, pp. 1867-1871, 2013.

[10] Y.M. Qian, D.P. Zhao, X.W. Xie, "The Research on the Ultimate Bearing Capacity of Soil around the Push-Extend Multi-under-Reamed Pile at Sliding Failure State," Applied mechanics and materials, vol. 578-579, pp. 232-235, 2014.

[11] G.L. Dai, W.M. Gong, X.L. Zhao, X.Q. Zhou, "Static Testing of Pile-Base Post-Grouting Piles of the Suramadu Bridge," Geotechnical Testing Journal, vol. 34, no. 1, pp. 1-16, 2011.

[12] D.W. Chang, B.S. Lin, S.H. Cheng, "Lateral load distributions on grouped piles from dynamic pile-to-pile interaction factors," International journal for numerical and analytical methods in geomechanics, vol. 33, no. 2, pp. 173-191, 2009.

[13] B. Aniruddha, C. Deepankar, "Serviceability-Based Finite-Element Approach on Analyzing Combined Pile-Raft Foundation,” International Journal of Geomechanics, vol. 20, no. 2, pp. 04019178, 2020.

[14] H.M. Chen, F.Q. Ban, X.W. Liu, "Relationship between Shear Strength Index c、 $\Phi$ of Unsaturated Soil and Water Content $\omega$," Journal of Hefei University of Technology (Natural Science Edition), vol. 29, no. 6, pp. 736-738, 2006.

[15] H. N. Mahmoud, Tobita, Tetsuo, Iai, Susumu, Karray, Mourad, "On the influence of vertical loads on the lateral response of pile foundation," Computers and geotechnics, vol. 55, pp. 392-403, 2014.

[16] Y.M. Qian, X.S. Yin, R.Z. Wang, "Analysis of Influence of Plate-expanded Position on Bearing Capacity of Single Pile,” Journal of Jilin Architectural and Civil Engineering Institute, vol. 03, pp. 1-3, 2010.

[17] Y.D. Chen, A. Deng, A.T. Wang, H.S. Sun, "Performance of screw-shaft pile in sand: Model test and DEM simulation," Computers and geotechnics, vol. 104, pp. 118-130, 2018.

[18] J. Hu, J.J. Gao, "Simplification of Vertical Live Loading for In-Service Bridge Pile Foundation and Application in Single Pile Model Test," in IOP Conference Series: Materials Science and Engineering, pp. 62065, 2018.

[19] Ghanim, A.Al. Athraa, Shafiqu, S. Qassun, Mohammed, Ibraheem, T. Asma, "A practical study of the geogrid-pile foundation system in loose sandy soil under the influence of Halabjah earthquake," in AIP conference proceedings, 2020.

[20] Y.M. Qian, Q.Y. Cheng, R.Z. Wang, "Research on the Test Method of the Concrete Expanded-Plates Pile,” Advanced in Engineering Research, vol. 39, pp. 1065-1070, 2015.

[21] X.J. Zou, H.T. Du, M. Zhou, X.W. Zhou, "Analysis of a Single Pile under Vertical and Torsional Combined Loads in Two-Layered Nonhomogeneous Soil," International Journal of Geomechanics, vol. 19, no. 6, pp. 04019054, 2019.

[22] D.S. Kong, M.X. Deng, Y. Liu, X.Y. Tan, "Study of the Force and Deformation Characteristics of Subsea Mudmat-Pile Hybrid Foundations," Polish maritime research, vol. 25, no. s3, pp. 43-53, 2018.

[23] Y.M. Qian, D.H. Ren, R.Z. Wang, "Analysis of Soil Characteristics Affecting Failure Behavior and Bearing Capacity of the Concrete Expanded-Plates Pile," The Open Construction and Building Technology Journal, vol. 9, pp. 188-191, 2015.

[24] B.H. Shen, D.X. He, Z.L. Liu, "The Generation and Characteristics of the Multi-section Squeezing and Expanding Pile,” Industrial Building, vol. 34, no. 3, pp. 1-4, 2004.

[25] Singh, T. Ningombam, Singh, Baleshwar, "Settlement Profile and Pile Load Distribution Under Vertical Load of Piled Raft Foundation in Clay," Geotechnical and geological engineering, vol. 38, no. 5, pp. 5229-5244, 2020

ISSN: 0010-8189

(C) CONVERTER 2020 